\title{
Makna Kesinambungan Kampanye Green Beauty oleh Kosmetik Garnier
}

\author{
Neldy Maria Lesilolo, Rustono Farady Marta, Rewindinar \\ lesiloloneldy@gmail.com,rmarta@bundamulia.ac.id,rewindinar@gmail.com
}

Program Studi Magister Ilmu Komunikasi, Program Pascasarjana, Universitas Bunda Mulia Jln. Lodan Raya No.2, Jakarta Utara 14430 - Indonesia

\begin{abstract}
The Garnier green beauty campaign conveys a message to the public through advertising media. The message is conveyed to the public regarding environmental activities that have a sustainable meaning. The green beauty campaign through advertising media shows Garnier's environmental friendly actions. Cause consumer behavior that turns into a form of responsible attitude. The purpose of this study was to determine the meaning of the sustainability of the green beauty campaign through Garnier's cosmetic advertising media. Researchers used a qualitative approach with Ferdinand de Saussure's semiotic analysis method which was signifier and signified. Methods of data collection with the method of documentation. The object of research was through the green beauty campaign advertisement and the subject of Garnier. The one-minute green beauty campaign ad is divided into seven scenes. The results of this study found the meaning of sustainability, by taking real action to become green beauty. Being green beauty is explained through verbal and non-verbal signs. Marked by each scene of the Garnier green beauty campaign advertisement, the meaning of sustainability is found. The real action starts from the production process to processing Garnier cosmetic waste.
\end{abstract}

Keywords: Campaign, Green Beauty, Semiotic, Sustainable

\begin{abstract}
Abstrak
Kampanye Garnier green beauty menyampaikan pesan kepada masyarakat melalui media iklan. Pesan yang disampaikan kepada khalayak mengenai kegiatan peduli lingkungan yang memiliki makna berkesinambungan. Kampanye green beauty melalui media iklan menunjukan aksi nyata Garnier yang ramah lingkungan. Menyebabkan perilaku konsumen yang berubah menjadi wujud sikap yang bertanggung jawab. Tujuan penelitian ini untuk mengetahui makna kesinambungan dari kampanye green beauty melalui media iklan kosmetik Garnier. Peneliti menggunakan pendekatan kualitatif dengan metode analisis semiotika Ferdinand de Saussure secara signifier dan signified. Metode pengumpulan data dengan metode dokumentasi. Objek penelitian melalui iklan kampanye green beauty dan subjek Garnier. Iklan kampanye green beauty yang berdurasi satu menit dibagi menjadi tujuh scene. Hasil Penelitian ini menemukan makna kesinambungan, dengan melakukan aksi nyata menjadi green beauty. Menjadi green beauty dijelaskan melalui tanda secara verbal dan non verbal. Ditandai melalui setiap scene iklan kampanye Garnier green beauty memiliki makna kesinambungan yang ditemukan. Aksi nyata dimulai dari proses produksi sampai pengolahan limbah kosmetik Garnier.
\end{abstract}

Kata Kunci: Green Beauty, Kampanye, Kesinambungan, Semiotika

\section{Pendahuluan}

Iklan adalah suatu penyampaian tanda, makna atau presepsi dari suatu merek kepada konsumennya. Iklan menjadi wadah penyampaikan pesan melalui media 
cetak dan media elektronik (Marta \& Septyana, 2015). Iklan adalah bentuk komunikasi yang diberikan kepada khalayak dalam bentuk komunikasi non-personal dengan beragam media penyampaian secara berbayar oleh suatu perusahaan, organisasi dan individu-individu. Iklan juga bisa menjadi media atau alat dalam proses mempromosikan barang dan jasa dalam dunia bisnis (Sampurna et al., 2020). Menurut Widiantoro (2015) iklan berdasarkan kepentingan dibagi menjadi bersifat komersial dan non komersial. Komersial untuk mencari keuntungan dan non komersial untuk kepentingan umum yang berkaitan dengan fenomena di masyarakat (Sasongko \& Marta, 2018).

Menurut Morissan (2010) iklan di media massa digunakan selain menyampaikan pesan dapat menciptakan citra merek yang menjadi daya tarik atau suatu simbol yang melekat dengan merek tersebut. Suatu perusahaan menyampaikan pesan menggunakan media iklan harus memanfaatkan iklan menjadi suatu produk yang melekat atau selalu diingat oleh konsumennya. Serta menyampaikan identitas dari perusahaan suatu merek. Hal ini yang akan menjadi daya tarik bagi perusahaan dalam menyampaikan iklan kepada konsumennya (Tianotak \& Asy'ari, 2019).

Kampanye suatu merek sering disampaikan melalui media iklan televisi, radio, maupun media siosial. Kampanye peduli lingkungan sangat banyak dilakukan seperti kampanye Savesharks di twitter oleh Riyanni pada tahun 2012. Kampanye yang menggunakan media sosial pertama bertujuan untuk menyadarkan masyarakat mengenai kerusakan ekosistem di laut dampak dari mengkonsumsi ikan hiu sebagai kuliner keren (Hersinta \& Sofia, 2020). Kampanye Garnier juga menggunakan semua media dengan menyebarkan melalui media iklan yang berdurasi satu menit dengan judul "Garnier Berkomitmen Menuju Green Beauty". Kampanye yang dilakukan memiliki tujuan yang berkesinambungan untuk menjaga lingkungan, utamanya menjadi masalah kekal di masyarakat Indonesia berupa sampah.

Sampah menjadi masalah di Indonesia terutama sampah plastik yang menjadi musuh besar kerusakan lingkungan. Tahun 2010 sampai sekarang sampah di Indonesia terus bertambah. Hal ini dibuktikan berdasarkan penelitian Jenna R. Jambeck dari Universitas Georgia tahun 2010. Indonesia menjadi negara penyumbang sampah urutan kedua terbesar setelah negara China dengan angka 275 juta ton sampah yang mencemari laut (Greenpeace, 2019). Meningkatnya jumlah penduduk dan kegiatan ekonomi juga meningkatkan jumlah volume sampah setiap tahun (Hariyanto, 2014).

Peran pemerintah sangat berperan penting dalam permasalahan lingkungan, bukan hanya pemerintah, tetapi masyarakat juga memiliki peran dalam permasalahan lingkungan. Mayarakat yang dimaksudkan sebagai produsen dan konsumen dalam suatu jasa atau barang (Andarsih \& Mayangsari, 2018). Pengolahan sampah bagian dari kegiatan yang berkesinambungan dengan tujuan meningkatkan menyelamatkan lingkungan dan menjadikan sampah sebagai sumber daya ekonomis. Menurut UU no.18 tahun 2008, sampah diartikan sebagai sisa aktifitas kehidupan masyarakat/mahkluk hidup yang akan diproses alam dalam bentuk padat atau secara alami (Oni et al., 2014).

Kampanye dilakukan sebagai salah satu gerakan pemerintah untuk menunjukan aksi nyata. Hal ini seperti yang dilakukan oleh Garnier, sebagai merek produk kosmetik yang mendukung pro-enviroment. Kampanye yang dilakukan Garnier green beauty, mengajak pengguna Garnier untuk bersama menjadi green beauty. Aksi green beauty ditujukan dengan perilaku penggunaan produk yang bertanggung jawab menjaga lingkungan dan memilah sampah serta menjadi 
penyelamat bumi. Pesan kampanye tersebut disampaikan melalui iklan yang disebarkan di seluruh media massa. Media massa menurut Cangara (2010) merupakan suatu alat komunikasi untuk menyampaikan pesan dengan jangkauan secara luas. Mencangkup semua jenis media seperti media elektronik, media internet, dan media cetak (Wahyudi, 2017).

Penelitian ini memiliki tujuan untuk mengetahui makna kesinambungan dari kampanye green beauty melalui tanda dari scene iklan kosmetik Garnier. Alasan penelitian menggunakan makna kesinambungan, berkaitan dengan tujuan kampanye merawat keindahan bumi dimulai dari diri sendiri. Membentuk kebiasaan masyarakat untuk bertanggung jawab secara terus - menerus mengelolah dan merawat bumi. Kesinambungan menurut Kamus Besar Bahasa Indonesia (KBBI) berasal dari kata sifat sinambung yang berarti berlanjut atau secara terus menerus. Secara garis besar kebersinambungan memiliki arti kelanjutan atau kontinuitas. Konsep kampanye green beauty untuk mengambil langkah nyata dalam memerangi limbah plastik dengan target 100 ton plastik pertahunnya. Jenis-jenis sampah plastik yang dapat dikumpulkan adalah seperti: PTE, PDTE, PVC, LDPE, dan PP. Dapat ditemukan dalam setiap kemasan produk di kosmetik Garnier.

\section{Metode Penelitian}

Metode penelitian kualitatif merupakan metode penelitian yang digunakan dalam penelitian ini. menurut Creswell (2010) Penelitian kualitatif merupakan penelitian yang memiliki sifat deskriptif dengan metode untuk mengeksplorasi dan pemahaman makna dari fenomena yang terjadi di masyarakat (Januarti \& Wempi, 2019). Peneliti menggunakan pendekatan kualitatif karena peneliti menganalisis makna kesinambungan dari iklan kampanye Garnier. Metode analisis menggunakan metode semiotika Ferdinan De Saussure. Saussure membagi tanda dalam konteks komunikasi manusia dibagi menjadi Signifier (penanda) dan Signified (petanda). Menurut Sobur (2014) signifier adalah tanda yang memiiliki aspek material atau dlihat secara jelas menggunakan logika. Sedangkan signified memiliki aspek mental, atau konsep pemikiran dari bahasa (Fanani, 2013).

Semiotika berasal dari kata Yunani "semeion" memiliki arti sebagai tanda. Ferdinand De Saussure menjelaskan (Sobur, 2017) Semiotika merupakan sebuah ilmu atau metode analisis yang mempelajari mengenai peran, pemahaman, dan arti dari sebuah tanda yang berada di dalam lingkungan masyarakat. Model semiotika Saurssure digunakan untuk menganalisis kampanye Garnier dari makna pesan yang disampaikan melalui iklan kepada masyarakat berkaitan dengan masalah lingkungan yang terjadi di Indonesia (Leonardo \& Junaidi, 2020).

Proses komunikasi terjadi ketika komunikator mengirim makna suatu objek dengan menggunakan tanda dan komunikan yang akan mendefinisikan tanda tersebut. Komunikasi verbal dapat digunakan dalam proses komunikasi secara sengaja maupun tidak sengaja(Lumampauw et al., 2020). Saussure menyebutkan objek dengan sebutan "referent" sebagai unsur tambahan dalam proses penandaan hubungan antara bahasa dan makna. Saussure juga mengumpamakan Signifier (penanda) dan signified (petanda) adalah satu kesatuan yang erat dan tidak terpisahkan atau saling melengkapi. Asumsi dari Saussure setiap tindakan manusia yang memiliki makna dan berfungsi sebagai tanda, maka terdapat sistem perbedaan dan persamaan dari makna itu (Halid, 2019). 
Studi dokumentasi merupakan cara pengumpulan data dalam penelitian ini. Menurut Guba dan Lincoln studi dokumen digunakan untuk kebutuhan penelitian dikarenakan dokumen dan rekaman merupakan sumber yang konstan, sehingga hasil pengkajian isi akan membuka kesempatan untuk lebih memperdalam objek pengetahuan terhadap sesuatu yang diteliti" (Nuraeni, 2014). Obyek penelitian adalah iklan kampanye "Garnier Berkomitmen Menuju Green Beauty" yang berdurasi satu menit dibagi menjadi tujuh scene. Sejalan dengan fenomena yang berlangsung dengan pro-enviroment. Subyek dalam penelitian ini adalah Garnier.

Teknik keabsaan data yang digunakan oleh peneliti menurut Meleong adalah ketekunan pengamatan. Karena dengan meningkatkan ketekunan pengamatan mendapatkan kepastian data secara sistematis. Keabsaan data dilakuakan untuk memenuhi kebenaran data berdasarkan sumber informasi yang dikumpulkan. Peneliti melakukan pengamatan melalui iklan kampanye Garnier (Lestari, 2017).

\section{Hasil Temuan dan Diskusi}

Analisis semiotika menjadi dasar analisis penelitian untuk menemukan makna kesinambungan yang terkandung dalam iklan kampanye green beauty pada kosmetik Garnier. Iklan dari group L'OREAL Group Company ini dibagi menjadi tujuh potongan scene dalam yang berdurasi satu menit. Kampanye ini didukung oleh Kementrian Lingkungan Hidup dan Kehutanan Republik Indonesia dan bekerjasama dengan perusahaan e-Recyle secara online dan offline. Ditayangkan pada media konvesional maupun online.

Tanggal 16 Febuari 2021 sudah ditonton sebanyak 57.364.273 kali sejak diposting pada tanggal 27 September 2020. Scene pertama dengan teknik pengambilan gambar medium shoot dan irama musik yang santai. Ditambah dengan dubbing suara "banyak yang kita lakukan untuk merawat diri". Memiliki makna kritikan kepada ego manusia yang selalu mengambil keindahan bumi demi kepentingan individu tanpa memikirkan dampak bagi lingkungan.

Tabel 1. Scene Pertama

\begin{tabular}{|c|c|c|}
\hline \multicolumn{2}{|c|}{ Tanda (Sign) : Seorang perempuan memetik bunga di taman } \\
\hline & & $\begin{array}{c}\text { Saat pembukaan video } \\
\text { menunjukkan tujuan video } \\
\text { ini dibuat untuk } \\
\text { menggunakan plastik daur } \\
\text { ulang melalui teks. Diawali } \\
\text { dengan burung yang } \\
\text { melintasi langit dengan } \\
\text { kicauan saat seorang } \\
\text { perempuan cantik memetik } \\
\text { bunga yang hendak } \\
\text { meletakan pada kepala } \\
\text { perempuan tersebut }\end{array}$ \\
\hline Penanda (signifier) & Pertanda (signified) \\
\hline
\end{tabular}

Sumber: YouTube Garnier

Scene kedua menggunakan teknik pengambilan gambar zoom shoot, ekstrim long shoot dan medium shoot. Audio yang dramatis, irama sedih dan dubbing "tapi 
untuk bumi ini”. Mendapatkan makna dampak dari keserakahan manusia. Kebiasaan manusia yang mengambil dari alam tanpa memberikan solusi untuk menjaga dan merawat bumi. Berdampak negatif pada lingkungan hidup seperti kekeringan, polusi dan kerusakan bumi lainnya.

Tabel 2. Scene kedua

\begin{tabular}{|c|c|}
\hline \multicolumn{3}{|c|}{ Tanda (Sign) : Kerusakan lingkungan } \\
\hline Pend & $\begin{array}{c}\text { Tanah yang subur menjadi } \\
\text { kering, langit tercemar } \\
\text { polusi, tumbuh - } \\
\text { tumbuhan mati. Hanya } \\
\text { tersisa bunga yang ada } \\
\text { dikepala perempuan yang } \\
\text { ditaman }\end{array}$ \\
\hline Penanda (signifier) & Pertanda (signified) \\
\hline
\end{tabular}

Sumber: YouTube Garnier

Scene ketiga menggunakan teknik pengambilan gambar zoom and extrem long shoot. Irama musik cepat dan kalimat ajakan dari dubbing "untukmu dan bumi kita Garnier memulai green beauty, sebuah langkah awal.”. Makna dari pesan yang diberikan untuk mengajak konsumennya bergabung dengan green beauty. Melakukan aksi nyata menjaga lingkungan dari tindakan kecil yang berdampak besar bagi lingkungan.

Tabel 3. Scene Ketiga

\begin{tabular}{|c|c|}
\hline Tanda (Sign) : Seorang perempuan menanam bunga ditanah yang kering \\
\hline Penanda (signifier) & $\begin{array}{c}\text { Seorang perempuan } \\
\text { menanam kembali bunga } \\
\text { yang dipetik ketanah yang } \\
\text { kering. Dari satu bunga } \\
\text { dapat mengembalikan } \\
\text { tanah yang kering menjadi } \\
\text { subur dan berubah menjadi } \\
\text { indah }\end{array}$ \\
\hline Pandified) \\
\hline
\end{tabular}

Sumber: YouTube Garnier

Scene keempat dengan teks vidio dari sumber alam yang berkelanjutan, dan mengurangi co2 \& konsumsi air. Irama musik yang cepat dengan tambahan dubbing untuk semua liner di rantai produksi dari proses produksi ramah lingkungan. Penggambilan gambar menggunakan teknik medium shoot. Memiliki makna Garnier melakukan aksi nyata dengan mengubah formula yang ramah lingkungan dan tidak 
menimbulkan polusi. Melakukan aksi dengan penggunaan bahan produksi dari alam dan penanaman kembali.

Tabel 4. Scene Keempat

\begin{tabular}{|c|c|c|}
\hline \multicolumn{3}{|c|}{ Tanda (Sign) : Proses produksi produk Garnier } \\
\hline & & $\begin{array}{c}\text { Proses produksi ditunjukan } \\
\text { dari bahan dari alam, } \\
\text { diolah sampai menjadi } \\
\text { kemasan yang akan } \\
\text { dipakai oleh konsumen } \\
\text { Garnier dengan bahan dan } \\
\text { kemasan yang ramah } \\
\text { lingkungan }\end{array}$ \\
\hline Penanda (signifier) & Pertanda (signified) \\
\hline
\end{tabular}

Sumber: YouTube Garnier

Scene kelima teknik pengambilan gambar medium shoot sampai ekstrim zoom shoot. Secara visual terbantu dengan logo reycle dan teks kemasan ramah lingkungan. Dengan irama musik yang cepat serta dubbing "sampai menggunakan kemasan yang nantinya dapat didaur ulang". Memiliki makna Garnier menunjukan aksi nyata bahwa, kemasan produk ramah lingkungan yang dapat didaur ulang tanpa harus dibuang.

Tabel 5. Scene Kelima

\begin{tabular}{|c|c|}
\hline \multicolumn{3}{|c|}{ Tanda (Sign) : Kemasan ramah lingkungan } \\
\hline Seorang perempuan \\
menggunakan produk \\
garnier sampai habis, \\
kemasan habis dipakai \\
tidak dibuang. Melainkan \\
dikumpukan kedalam \\
suatu wadah dengan \\
kemasan habis pakai \\
garnier lainnya.
\end{tabular}

Sumber: YouTube Garnier

Scene keenam pengambilan gambar dengan teknik medium shoot dan dubbing ajakan "kini kamu bisa menjadi bagian green beauty dengan mendaur ulang kemasan plastik bekas pakaimu. Kunjungi garnier.co.id /greenbeauty untuk tau lebih lanjut". Adapun visual seperti teks website dan logo reycle yang tertera pada kardus. Memiliki makna mengajak konsumen sebagai green beauty sebagai aksi nyata peduli lingkungan yang berdampak positif. Dengan cara mengumpulkan kemasan produk 
Garnier habis pakai, kemudian membawa pada tempat daur ulang yang tersedia di aplikasi e-reycle. sebagai bagian dari green beauty.

Tabel 6. Scene Keenam

\begin{tabular}{|c|c|}
\hline \multicolumn{2}{|c|}{ Tanda (Sign) : Proses Reycle kemasan Garnier } \\
\hline
\end{tabular}

Sumber: YouTube Garnier

Scene ketujuh sebagai penutup iklan kampanye, teknik pengambilan gambar secara medium shoot. Serta ajakan tertulis dengan mengunjungi website Garnier dan logo kerjasama e-recyle dan Kementrian Lingkungan Hidup dan Kehutanan Republik Indonesia. Memiliki makna keseriusan sebagai produsen yang mengurangi masalah lingkungan terutama sampah plastik. Membangun hubungan kerjasama bersama pihak pemerintah dan konsumennya untuk memberikan solusi dan aksi nyata sebagai green beauty.

Tabel 7. Scene Ketujuh

\begin{tabular}{|c|c|}
\hline \multicolumn{2}{|c|}{ Tanda (Sign) : Lingkungan hijau dan kerjasama } \\
\hline & $\begin{array}{c}\text { Menjadi green beauty } \\
\text { untuk merawat } \\
\text { lingkungan sehingga } \\
\text { menjadi subur. Garnier } \\
\text { menunjukan komitmen } \\
\text { dengan bekerjasama } \\
\text { dengan e-recyle, dan } \\
\text { mendapatkan dukungan } \\
\text { langsung dari } \\
\text { Kementrian Lingkungan } \\
\text { Hidup dan Kehutanan } \\
\text { Republik Indonesia }\end{array}$ \\
\hline Penanda (signifier) & Pertanda (signified) \\
\hline
\end{tabular}

Sumber: YouTube Garnier 
Iklan tersebut menampilkan fenomena yang menjadi masalah dibumi dalam menjaga lingkungan. Menggambarkan dampak jika manusia mengambil dari alam tanpa mengelola kembali sumber daya alam dan menggunakan bahan - bahan yang menimbulkan kerusakan lingkungan. Garnier mencontohkan sebagai brand kosmetik yang berani untuk mengubah proses produksi dan bahan yang ramah lingkungan. Menunjukan tanda secara lisan dan tulisan yang mempertegas tujuan mengajak melakukan kebiasan seperti green beauty.

Makna kesinambungan ditunjukan pada scene-scene menunjukan kebiasan manusia yang dapat menjaga lingkungan secara terus menerus. Seperti gambaran green beauty mengetahui dampak baik buruk dalam menentukan produk yang digunakan dengan konsep ramah lingkungan dan dapat didaur ulang kembali. Green beauty digambarkan sebagai kesempatan untuk menciptakan dampak positif menuju keberlanjutan bagi semua orang. Melalui aksi nyata keberlanjutan dari proses produksi sampai pengolahan limbah produk kosmetik Garnier.

\section{Simpulan}

Berdasarkan hasil analisis semiotika Ferdinand de Saussure untuk mengungkapkan makna kesinambungan yang terdapat dalam iklan kampanye green beauty. Menjawab tujuan dari penelitian melalui unsur - unsur analisis semiotika untuk mengungkapkan tanda secara verbal dan nonverbal dalam mempresentasikan makna kesinambungan. Melalui iklan ini masyarakat diajak untuk menjadi bagian green beauty sebagai aksi nyata keberlanjutan. Green beauty sebagai kesempatan semua orang untuk menciptakan dampak positif menuju keberlanjutan secara luas. Garnier melakukan aksi nyata melalui proses produksi sampai pengolahan limbah produk kosmetik. Hal ini dibuktikan sebagai proses yang berkesinambungan untuk menyelesaikan masalah lingkungan dalam program kampanye "Garnier berkomitmen menuju green beauty".

\section{Ucapan Terima Kasih}

Peneliti mengucapkan terima kasih kepada semua pihak yang telah membantu dan terlibat dalam proses penyusunan penelitian ini. Terutama kepada Tuhan Yang Maha Esa, Garnier, Universitas Bunda Mulia, dan Universitas Tarumanagara.

\section{Daftar Pustaka}

Andarsih, Y. S., \& Mayangsari, I. D. (2018). Strategi Komunikasi Program Bandung Cleanaction dalam Mengkampanyekan Gerakan Pungut Sampah (GPS). Dialektika, Jurnal Ilmu Komunikasi, https://journals.telkomuniversity.ac.id/

Fanani, F. (2013). Semiotika Strukturalisme Saussure. Jurnal The Messenger, 5(1), 10. https://doi.org/10.26623/themessenger.v5i1.149

Greenpeace. (2019). Krisis Belum Terurai Rekaptulasi Temuan Ausdit Merek Sampah Plastik Tahun 2016-2019 di Indonesia.

Halid, R. (2019). Analisis Semiotika Ferdinand de Saussure pada Novel Manjali dan Cakrabirawa Karya aAyu Utami. MUHAMMADIYAH MAKASSAR.

Hariyanto. (2014). Pengelolaan Sampah Di Kota Semarang Untuk Menuju Kota Bersih. Jurnal Geografi: Media Informasi Pengembangan Dan Profesi 
Neldy Maria Lesilolo, Rustono Farady Marta, Rewindinar: Makna Kesinambungan Kampanye Green Beauty oleh Kosmetik Garnier

Kegeografian, 11(2), 237-246. https://doi.org/10.15294/jg.v11i2.8031

Hersinta, \& Sofia, A. (2020). Social Media, Youth and Environmental Low-Risk Activism: A Case Study of Savesharks Indonesia Campaign on Twitter. Aspiration Journal, 1(2), 113-134.

Januarti, J., \& Wempi, J. A. (2019). Makna Tenun Ikat Dayak Sintang Ditinjau Dari Teori Semiotika Sosial Theo Van Leeuwen. Bricolage: Jurnal Magister Ilmu Komunikasi, 5(01), 073. https://doi.org/10.30813/bricolage.v5i01.1743

Leonardo, R., \& Junaidi, A. (2020). Kritik Sosial dalam Stand Up Comedy (Analisis Semiotika Show "Pragiwaksono World Tour"). Koneksi, 4(2), 185. https://doi.org/10.24912/kn.v4i2.8077

Lestari, F. (2017). Pesan Budaya Lokal Dalam Tayangan Televisi (Analisis Semiotik Pada Acara Televisi "Indonesia Bagus" Episode Yogyakarta Di Stasiun NET $T V$ ) [MUHAMMADIYAH MALANG]. http://eprints.umm.ac.id/37056/

Lumampauw, A., Lestari, R., Marta, R. F., \& Fernando, J. (2020). Awakening Revealed through Rose' s Visual Analysis on \# LangkahHijau Commercial Advertisement Kebangkitan Terungkap Melalui Analisis Visual Rose pada Iklan Komersial \# LangkahHijau. 08(02), 121-133. https://journal.budiluhur.ac.id/index.php/avantgarde/article/view/1231

Marta, R. F., \& Septyana, V. (2015). Semiotika Pemasaran pada Brand Value Melalui Sign Berupa Layout Berita dan Iklan Ibadah Haji (Studi Komparasi pada Harian Pos Kota dengan Rakyat Merdeka). Semiotika : Jurnal Komunikasi, 9(2), 482-508. https://journal.ubm.ac.id/index.php/semiotika/article/download/24/18

Nuraeni, A. (2014). Pembelajaran PAI untuk Siswa Tunarungu ( Studi Deskriptif Pelaksanaan Pembelajaran Pada SMPLB Muhammadiyah Bayongbong-Garut Kelas VIII Semester Genap Tahun Ajaran 2013/2014) [Universitas Pendidikan Indonesia]. http://repository.upi.edu/11394/

Oni, A., Subair, \& Nasution, E. (2014). Strategi Nafkah Pemulung di Tempat Pembuangan Sampah Akhir Toisapu, Ambon (Sebuah Kajian Sosiologis). Dialektika: Jurusan Sosiologi Agama, 8(1), 1-16. https://jurnal.iainambon.ac.id/index.php/index

Sampurna, A., Agustina, M., \& Marta, R. F. (2020). Menelisik Pariwara Rinso Warna Versi Badut dalam Logika Semiologi Barthes. Jurnal Komunikasi Profesional, 4(2). https://doi.org/10.25139/jkp.v4i2.2841

Sasongko, Y. P. D., \& Marta, R. F. (2018). Ekspresi Identitas Melalui Relasi Ayah Dan Anak Pada Iklan YouTube Grab Official. Bricolage : Jurnal Magister Ilmu Komunikasi, 4(02), 118. https://doi.org/10.30813/bricolage.v4i02.1656

Tianotak, J., \& Asy'ari, N. A. S. (2019). Makna Tagline 'Menjadi Yang Terbaik' Iklan Telkomsel Versi Pilot Papua Riko Kabak. Bricolage: Jurnal Magister Ilmu Komunikasi, 5(01), 049. https://doi.org/10.30813/bricolage.v5i01.1742

Wahyudi, arif. (2017). Konstruksi Realitas Berita Infotainment (Analisis Framing Rubrik Infotaiment Kompas.com dan JPNN.com edisi 10-15 Oktober 2016) [Muhamadiyah Malang]. In Jurnal Sains dan Seni ITS (Vol. 6, Issue 1). http://repositorio.unan.edu.ni/ 